Eva Julia Lohse

\title{
Rechtsangleichungsprozesse in der Europäischen Union
}

Instrumente, Funktionsmechanismen und Wirkparameter effektiver Harmonisierung

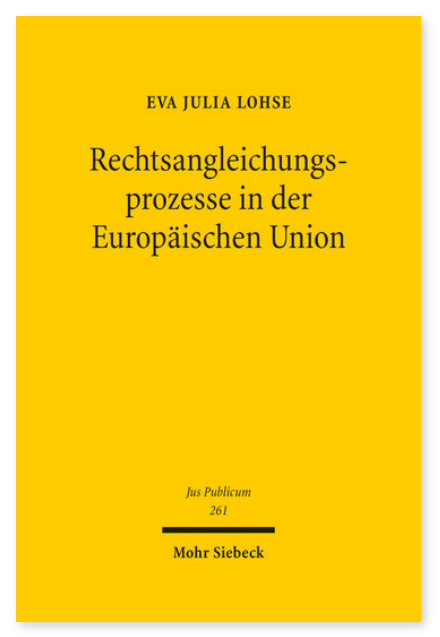

2017. XLI, 752 Seiten. JusPubl 261

ISBN 978-3-16-154598-6

DOI 10.1628/978-3-16-154598-6

eBook PDF $159,00 €$

ISBN 978-3-16-154555-9

Leinen $159,00 €$
Eva Julia Lohse befasst sich mit grundlegenden Fragen der Rechtsangleichung in der Europäischen Union. Nach welchen rechtlichen Mechanismen läuft diese ab? Lassen sich beim Vergleich verschiedener (historischer) Angleichungsprozesse in unterschiedlichen Mitgliedstaaten Muster der Rechtsangleichung erkennen? Lassen sich aus diesen Mustern wiederum Parameter erkennen, die zum Erfolg oder Misserfolg eines Angleichungsvorgangs beitragen können? Liegen diese auf unionaler oder auf mitgliedstaatlicher Ebene? Wie muss ein Angleichungsinstrument letztlich gestaltet werden, um erfolgreich zu sein? Ist es wichtiger, nationale Eigenheiten zu schützen oder von europäischer Ebene genaue Vorgaben zu machen und diese auch kontrollieren zu können? Betrachtet werden sowohl Richtlinien als auch primärrechtliche (»negative«) Harmonisierungsprozesse; der Schwerpunkt liegt bei Angleichungsvorgängen in Deutschland und England. Als Deutungsmuster wird zum einen das Paradigma der »legal transplants« verwendet, zum anderen rechtssoziologische Modelle der »Akzeptanz« und kulturtheoretische Überlegungen.

Die Arbeit wurde mit dem Werner-von Simson-Preis 2016 ausgezeichnet.

Eva Julia Lohse Geboren 1979; Studium der Rechtswissenschaften an den Universitäten Erlangen-Nürnberg, Lausanne und Kent (UK); Wissenschaftliche Mitarbeiterin an den Universitäten Freiburg und Erlangen-Nürnberg; 2014 Promotion; 2015 Habilitation; WS 2015/16 Vertretung des Lehrstuhls für Rechtsphilosophie an der Universität Freiburg; SoSe 2016 Vertretung des Lehrstuhls für Völkerrecht an der Universität Augsburg.

Jetzt bestellen:

https://mohrsiebeck.com/buch/rechtsangleichungsprozesse-in-der-europaeischen-union-9783161545986?no_cache=1 order@mohrsiebeck.com

Telefon: +49 (0)7071-923-17

Telefax: +49(0)7071-51104 